\title{
Incidence of preclinical manifestations of mantle cell lymphoma and mantle cell lymphoma in situ in reactive lymphoid tissues
}

\author{
Patrick Adam ${ }^{1}$, Ana-Iris Schiefer ${ }^{2}$, Sophie Prill ${ }^{1}$, Tobias Henopp ${ }^{1}$, \\ Leticia Quintanilla-Martínez ${ }^{1}$, Hans-Christian Bösmüller ${ }^{3}$, Andreas Chott ${ }^{4}$ and Falko Fend ${ }^{1}$ \\ ${ }^{1}$ Institute of Pathology and Comprehensive Cancer Center (CCC), University of Tübingen, Tübingen, \\ Germany; ${ }^{2}$ Clinical Institute of Pathology, Medical University Vienna, Vienna General Hospital, Vienna, \\ Austria; ${ }^{3}$ Department of Pathology, Krankenhaus Barmherzige Schwestern Linz, Linz, Austria and \\ ${ }^{4}$ Institute of Pathology and Microbiology, Wilhelminenspital, Vienna, Austria
}

\begin{abstract}
Recently, the occurrence of cyclin D1-positive B cells with mantle cell lymphoma phenotype in the inner mantle zones of morphologically inconspicuous lymph nodes has been described and termed mantle cell lymphoma 'in situ'. Prevalence and clinical significance of this lesion and related minimal mantle cell lymphoma infiltrates in reactive lymphoid tissues of healthy individuals, and of mantle cell lymphoma patients are unknown. All 1292 reactive lymph nodes from unselected consecutive surgical specimens of 131 patients without a history of lymphoma obtained over a 3-month period were stained for cyclin D1. In addition, all morphologically reactive lymph nodes and benign-appearing extranodal lymphoid infiltrates of patients diagnosed with mantle cell lymphoma in the years 2000-2011 were studied. Samples predating the lymphoma diagnosis for at least 2 months were available from $37 / 423(9 \%)$ patients. A mantle cell lymphoma 'in situ' was not identified in any of the two groups. However, in four patients with subsequent mantle cell lymphoma diagnosis, an early manifestation of mantle cell lymphoma was detected retrospectively, antedating the lymphoma diagnosis for 2-86 months. In six mantle cell lymphoma patients, only small groups of cyclin D1-positive cells in morphologically reactive extranodal infiltrates were detected $>2$ months before the diagnosis of mantle cell lymphoma (range 3-59 months). Mantle cell lymphoma 'in situ' is an extremely rare phenomenon in morphologically reactive lymph nodes, in line with the low prevalence of $t(11 ; 14)$-positive cells described in the peripheral blood of a healthy population. In mantle cell lymphoma patients, however, immunohistochemically detectable infiltrates of mantle cell lymphoma cells antedating the lymphoma diagnosis were found in a significant proportion of cases $(10 / 37=27 \%)$. These consisted either of early mantle cell lymphoma with mantle zone growth pattern, or small extranodal accumulations of cyclin D1 + cells, whereas typical mantle cell lymphoma 'in situ' was not detected.
\end{abstract}

Modern Pathology (2012) 25, 1629-1636; doi:10.1038/modpathol.2012.117; published online 13 July 2012

Keywords: mantle cell lymphoma 'in situ'; preclinical manifestations of mantle cell lymphoma; reactive lymph nodes

Mantle cell lymphoma accounts for about $7 \%$ of all non-Hodgkin lymphomas of B-cell lineage in adults, and in contrast to other small B-cell lymphomas shows in most cases an aggressive clinical course

Correspondence: Dr P Adam, Institute of Pathology and Comprehensive Cancer Center (CCC), Eberhard-Karls-University Tübingen, Liebermeisterstr. 8, 72076 Tübingen, Germany.

E-mail: patrick.adam@med.uni-tuebingen.de

Received 14 March 2012; revised 11 May 2012; accepted 14 May 2012; published online 13 July 2012 with a median survival of 3-5 years. ${ }^{1}$ Mantle cell lymphoma is characterized by the chromosomal translocation $\mathrm{t}(11 ; 14)(\mathrm{q} 13 ; \mathrm{q} 32)$ resulting in the constitutive expression of the cyclin D1 protein in almost all cases. ${ }^{1}$

Interestingly, rare B-cells carrying the $t(11 ; 14)$ translocation can also be found in the peripheral blood of healthy individuals. ${ }^{2,3}$ Hirt et $a l^{4}$ found circulating $t(11 ; 14)$-positive cells in one of 100 healthy individuals at a frequency of $0.6 \mathrm{t}(11 ; 14)$ translocation copies $/ 10^{5}$ peripheral 
blood mononuclear cells. In contrast to this low prevalence, t(14;18)-positive B cells, ie, follicular lymphoma-like B cells were detected in 39 of 86 individuals $(45 \%)$ in the same study. Both chromosomal translocations are considered to arise from a similar mechanism of illegitimate repair of $V(D) J$ recombination intermediates with recombinasemediated breaks in the IgH gene locus and doublestrand DNA breaks of different origin at the oncogene loci. ${ }^{5}$ A recent study by Lecluse et $a l^{6}$ extended this data significantly by showing that $\mathrm{t}(11 ; 14)$-positive B-cell clones with identical CyD1/ $\mathrm{J}_{\mathrm{H}}$ junctions can persist over a long period of time in the blood of healthy individuals, up to 9 years after the initial sampling. This is far longer than the average life span of normal naive B lymphocytes and suggests the presence of long-lived precursor cells, from which circulating cells are released. ${ }^{6}$

A possibly related finding is the occurrence of strongly cyclin D1-expressing, t(11;14)-positive B cells in non-expanded mantle zones surrounding reactive follicles without morphological evidence for involvement by mantle cell lymphoma. This finding has been designated mantle cell lymphoma 'in situ'. ${ }^{7}$ It has been stressed that the diagnosis of mantle cell lymphoma 'in situ' requires a totally preserved histoarchitecture of the involved lymph node. ${ }^{7}$ Mantle cell lymphoma 'in situ' sometimes coexists in lymph nodes involved by other B-NHL, and may also occur in morphologically uninvolved tissues of mantle cell lymphoma patients. In a recent series, most patients with an incidentally diagnosed mantle cell lymphoma 'in situ' did not show progression to overt disease, irrespective of whether treatment had been administered or not. ${ }^{8}$ Other cases better diagnosed as 'early' mantle cell lymphoma essentially feature a more marked expansion of the mantle zone of reactive follicles, sometimes also with the appearance of primary follicles. ${ }^{9}$ These patients commonly have more widespread disease and hence should better be designated as early mantle cell lymphoma with mantle zone/nodular growth pattern. ${ }^{7,8}$

Strictly defined, mantle cell lymphoma 'in situ' might represent a very early stage of mantle cell lymphoma development, or even a pre-neoplastic state, requiring further genetic alterations or immunological events for full neoplastic transformation. The clinical significance of mantle cell lymphoma 'in situ' is not yet clear, partially because the true prevalence of this finding in the general population, and also in patients with manifest mantle cell lymphoma is not known. Therefore, we were interested in determining (1) how frequent mantle cell lymphoma 'in situ' or other early mantle cell lymphoma manifestations can be identified in reactive lymph nodes from patients without evidence of lymphoma, as a surrogate for the prevalence in healthy individuals, and (2) the prevalence of mantle cell lymphoma 'in situ' and similar early manifestations in morphologically reactive lymph nodes and other tissues with significant lymphoid infiltrates in patients with mantle cell lymphoma obtained at least 2 months before the diagnosis of lymphoma.

\section{Materials and methods}

\section{Case Selection}

All 1292 lymph nodes from 131 patients (78 male, 54 female, mean age: 61 years, range 18-91 years; median five lymph nodes per patient) consecutively submitted in a 3-month period to the Institute of Pathology of the University of Tübingen, Germany, were included in the study. Lymph nodes of 113 of the 131 patients $(=86 \%)$ had been removed for oncological staging of solid tumors. The remainder had a diagnosis of inflammatory diseases (eg, diverticulitis) or nonspecific lymphadenopathy. None of the patients had a history of mantle cell lymphoma, or a mantle cell lymphoma manifestation at another site. The same cohort had been examined for the prevalence of follicular lymphoma 'in situ'. ${ }^{10}$ In addition, all 423 patients diagnosed with mantle cell lymphoma during the years 20002011 from three Institutes of Pathology (Vienna General Hospital of Medical University Vienna, Austria; Krankenhaus Barmherzige Schwestern Linz, Austria and University of Tübingen, Germany) were screened for available reactive lymph nodes, lymphatic tissues (tonsils and appendices) and tissues with morphologically reactive lymphoid infiltrates. From 37 of these 423 (9\%) patients relevant tissue samples antedating the diagnosis of mantle cell lymphoma for $>2$ months were available (6 nodal, 24 extranodal and 7 both).

The study was approved by the Local Ethics Committee.

\section{Immunohistochemical Analysis}

All lymph nodes underwent routine histological examination, and were stained for cyclin D1 using a monoclonal rabbit antibody (clone SP4, Lab Vision, Fremont, CA, USA; dilution 1:40). In addition, tumors were stained for CD20 (dilution 1:500; Dako, Hamburg, Germany), CD5 (Novocastra, Berlin, Germany; dilution 1:100) and Ki67 (dilution 1:200; Dako). Immunohistochemical staining was performed on formalin-fixed, paraffin-embedded tissue sections on an automated immunostainer (Ventana Medical Systems ${ }^{\circledR}$, Tucson, AZ, USA) following the manufacturer's protocols. A part of the cyclin D1-positive cases were also stained for the transcription factor SOX11 (dilution 1:50; Sigma, Munich, Germany).

\section{Fluorescence In Situ Hybridization (FISH)}

In selected cases containing a sufficient number of aggregated cyclin D1-positive cells in the infiltrates, 
a FISH analysis was additionally performed, using a break-apart probe for the cyclin D1 gene locus (Vysis LSI CCND1 Dual Color Break Apart Rearrangement Probe, Abbott Molecular, Wiesbaden, Germany), indicative for the chromosomal translocation $\mathrm{t}(11 ; 14)(\mathrm{q} 13 ; \mathrm{q} 32)$.

\section{Clonality Analysis}

A comparative clonality analysis of the preclinical infiltrates and the manifest mantle cell lymphomas was performed in cases with sufficient tissue left (cases 1, 6, 7 and 9). DNA used for PCR was extracted from $10-\mu \mathrm{m}$ paraffin sections after laser capture microdissection, dewaxing and proteinase $\mathrm{K}$ digestion applying the standard phenol/chloroform purification procedures. The PCR for IgH framework 2 and 3 gene rearrangements was performed as described previously using 0.5 U Phusion Hot Start DNA Polymerase and $200 \mathrm{ng}$ of genomic DNA (Finnzymes, Woburn, MA, USA). ${ }^{11}$ Slightly modified amplification conditions were carried out with an initial denaturation step of $98^{\circ} \mathrm{C}$ (30 s), 40 cycles $\left(98^{\circ} \mathrm{C} 10 \mathrm{~s}, 60^{\circ} \mathrm{C} 30 \mathrm{~s}\right.$ and $72^{\circ} \mathrm{C} 30 \mathrm{~s}$ ) and a final step of $10 \mathrm{~min}$. The $\mathrm{JH}$ primer was modified with $\mathrm{D} 4$ fluorescent dyes (Sigma-Aldrich, St Louis, MO, USA). For Genescan analysis $0.5 \mu \mathrm{l}$ of the PCR products were mixed with a sample loading solution containing $0.24 \mu \mathrm{l}$ DNA Size Standard 400 (Beckman Coulter, Brea, CA, USA). The products were separated by capillary electrophoresis on the GenomeLab GeXP Genetic Analysis System and analyzed by the GenomeLab GeXP software 10.2 (Beckman Coulter).

\section{Results}

\section{Cyclin D1 Staining in Reactive Lymph Nodes}

The expression of cyclin D1 was investigated immunohistochemically in 1292 consecutively submitted lymph nodes of 131 patients. Endothelial cells and histiocytes were used as internal control. Cyclin D1-positive B cells were not identified in any case, indicating that the prevalence of mantle cell lymphoma 'in situ' in the normal population is extremely low.

\section{Cyclin D1 Staining in Patients with Known MCL}

To investigate how often mantle cell lymphoma 'in situ' and other minimal mantle cell lymphoma infiltrates might precede the diagnosis of mantle cell lymphoma, morphologically reactive lymph nodes, lymphatic tissues and tissues with morphologically reactive lymphocytic infiltrates antedating the diagnosis of mantle cell lymphoma for $>2$ months available from 37 of $423(9 \%)$ mantle cell lymphoma patients were analyzed for the expression of cyclin D1. The results are summarized in Table 1: In 10 out of these $37(27 \%)$ cases, cyclin D1 + B cells were identified. In six of these cases (cases 1-6) only scattered lymphoid aggregates were present that contained cyclin D1 + B cells. In case 3, an 84-yearold male was diagnosed with hyperplasia of the prostate with chronic nonspecific inflammation. Immunohistochemical analysis showed aggregates of cyclin D1 + B cells in these lymphoid infiltrates (Figures 1a-c). In general, these cells had a low proliferation rate. These six cases were interpreted as preclinical extranodal manifestation of mantle cell lymphoma and antedated the diagnosis of mantle cell lymphoma with a median of 23 months (3-61 months). Four of these six cases (cases 2, 4, 5 and 6) could additionally be evaluated for SOX11, and all four cases showed nuclear expression of SOX11.

The remaining four cases (cases 7-10) showed morphologically inconspicuous, but manifest infiltrates of early mantle cell lymphoma, antedating the clinical diagnosis of mantle cell lymphoma between 2 and 86 months (median 5 months). In case 7, a 58-year-old male patient, a lobectomy was performed because of large cell lung cancer.

Table 1 Clinical characteristics of MCL patients with a preclinical manifestation

\begin{tabular}{|c|c|c|c|c|}
\hline Case & Age/sex & Site & MCL diagnostic site & $\begin{array}{c}\text { Months to } \\
\text { MCL diagnosis }\end{array}$ \\
\hline \multicolumn{5}{|c|}{ Minimal MCL infiltrations } \\
\hline 1 & $66 / \mathrm{M}$ & Gastric mucosa & Pharynx & 23 \\
\hline 2 & $78 / \mathrm{M}$ & Colon adenomas & Iliacal lymph node & 23 \\
\hline 3 & $84 / \mathrm{M}$ & Prostate hyperplasia (TUR) & Bone marrow & 61 \\
\hline 4 & $66 / \mathrm{M}$ & Leiomyoma of urinary bladder & Bone marrow & 59 \\
\hline 5 & $57 / \mathrm{M}$ & Papillary urothelial carcinoma low grade pTa & Bone marrow & 14 \\
\hline \multirow[t]{2}{*}{6} & $69 / \mathrm{M}$ & Papillary urothelial carcinoma low grade pTa & Submental lymph node & 3 \\
\hline & & & Median: & 23 \\
\hline \multicolumn{5}{|c|}{ MCL with mantle zone growth pattern } \\
\hline 7 & $58 / \mathrm{M}$ & Large cell lung cancer & Retroperitoneal mass & 86 \\
\hline 8 & $76 / \mathrm{M}$ & Appendix, mesenterial lymph nodes & Cervical lymph node & 8 \\
\hline 9 & $87 / \mathrm{F}$ & Sigma diverticulitis, adnexae & Bone marrow & 2 \\
\hline \multirow[t]{2}{*}{10} & $75 / \mathrm{F}$ & Chronic bursitis & Cervical lymph node & 2 \\
\hline & & & Median: & 5 \\
\hline
\end{tabular}


Peritumoral lymph nodes revealed early involvement by mantle cell lymphoma with a mantle zone growth pattern not identifiable by conventional H\&E staining. In addition, small aggregates of cyclin $\mathrm{D} 1+$ cells were identified in circumscribed lymphoid infiltrates, initially interpreted as chronic inflammation (Figures 1d-h). A diagnosis of manifest mantle cell lymphoma was established 86
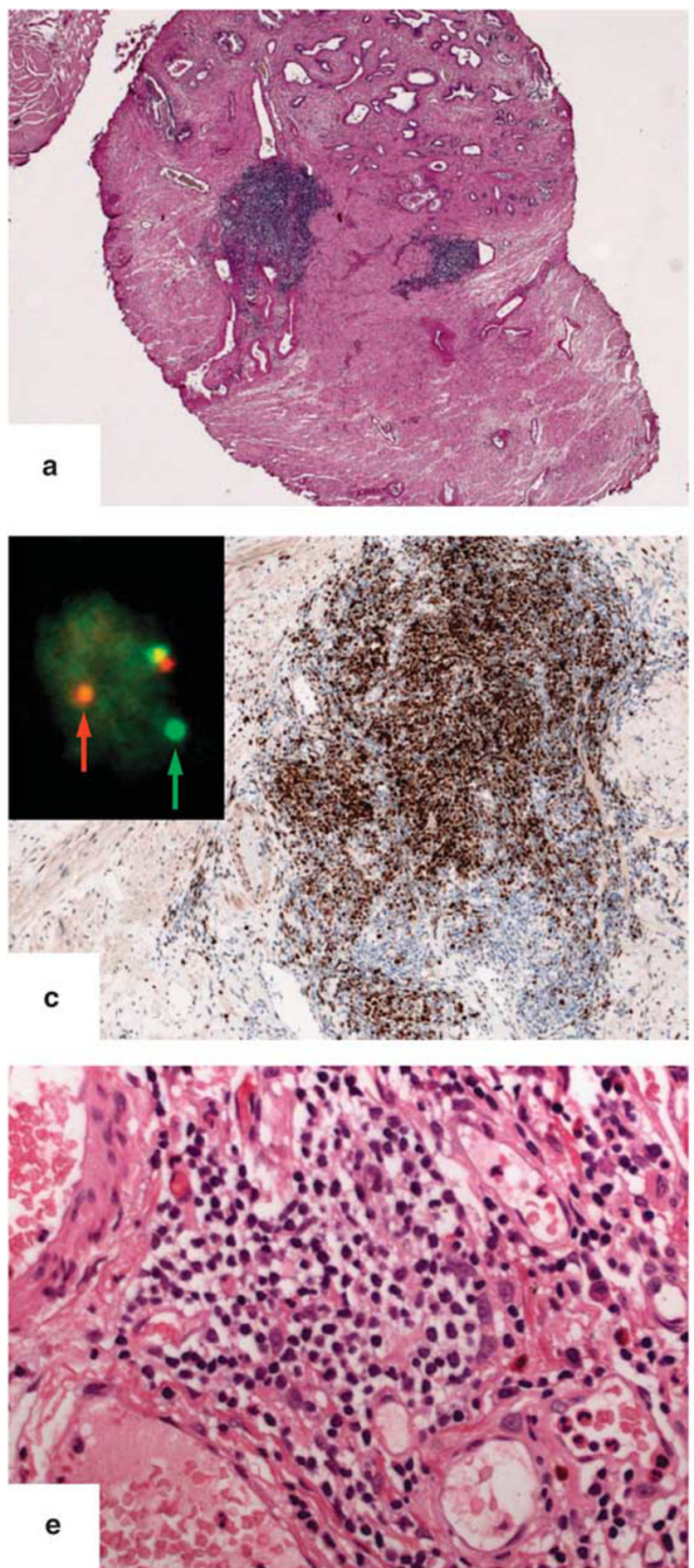

Figure 1 For caption see next page. months later. Two of the four cases (cases 9 and 10), an 87- and a 75-year-old female, respectively, showed dense extranodal lymphoid infiltrates surrounding a colonic diverticulitis and a chronic bursitis, respectively, initially interpreted as chronic inflammation. Immunohistochemical staining for cyclin D1 revealed dense nodular and mantle zone aggregates of cyclin D1 + B cells (case 9,
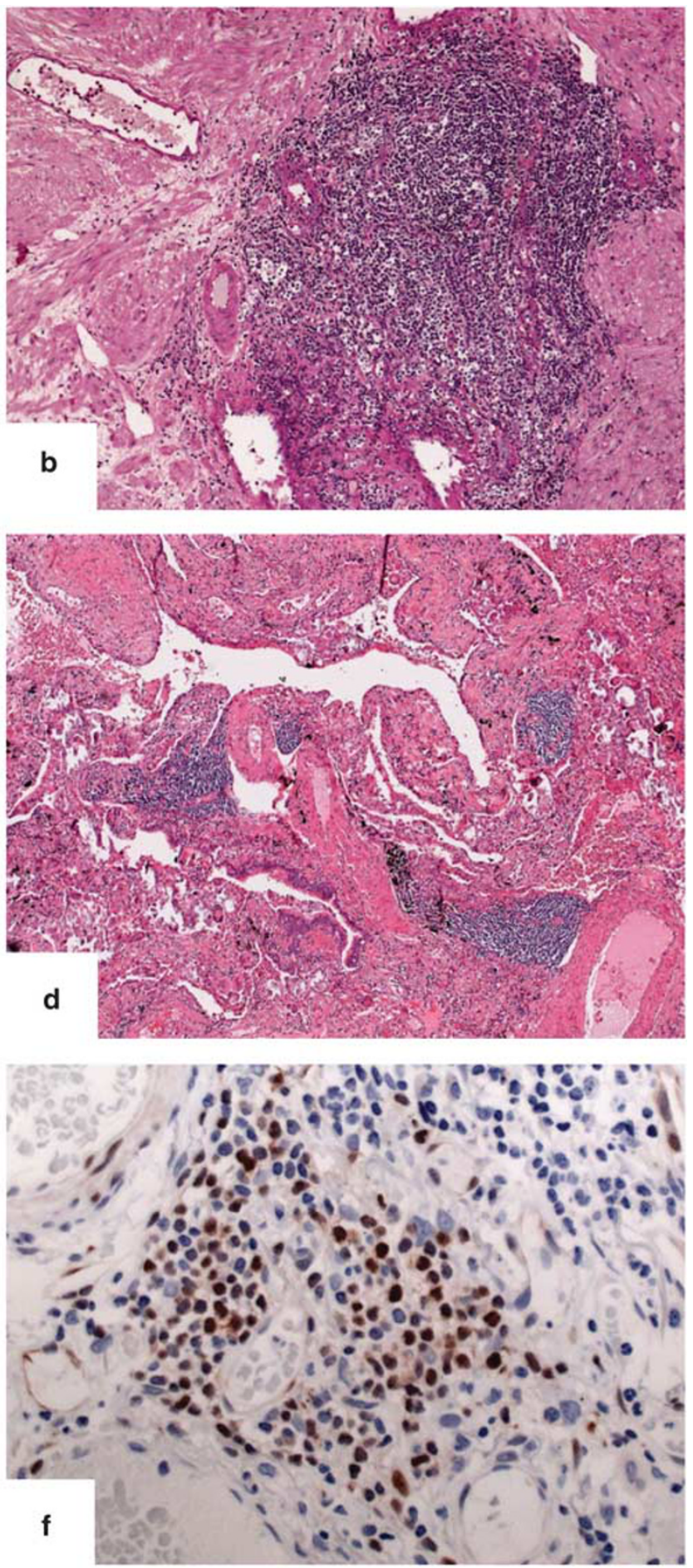

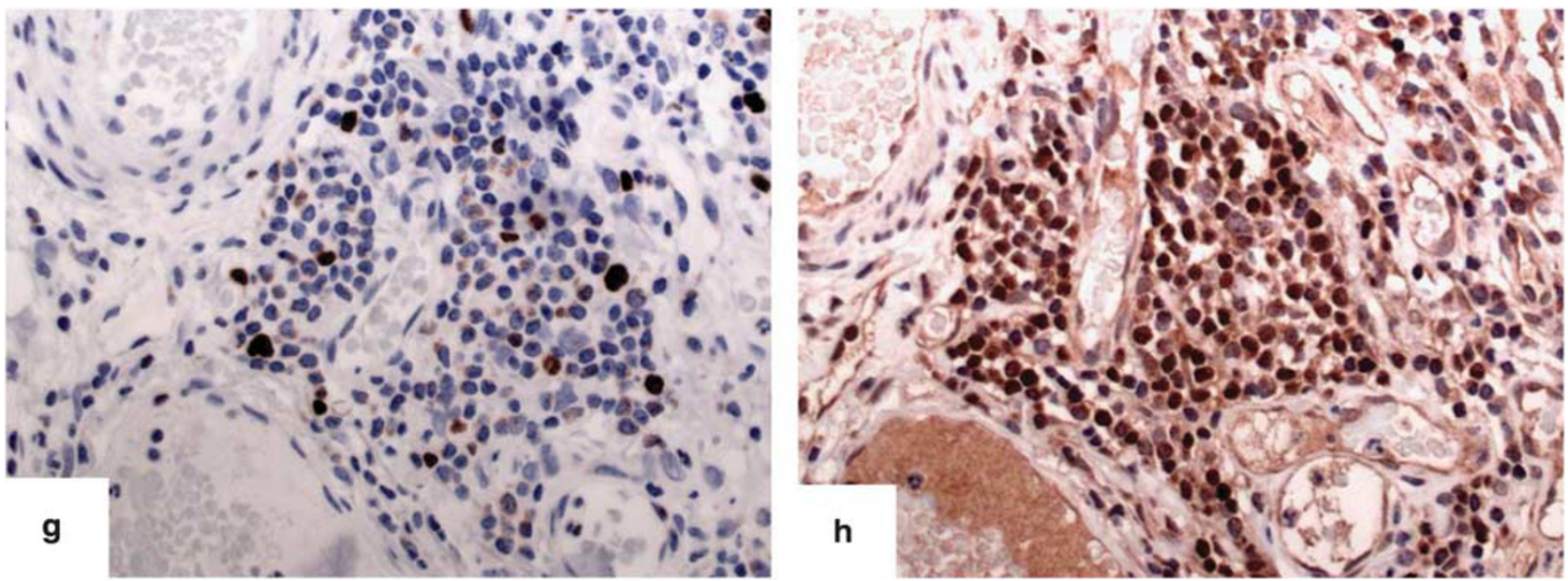

Figure 1 (a-h) Preclinical manifestations in mantle cell lymphoma patients. (a-c) Case 3: prostate resection. (a and b) Lymphoid infiltrates were initially interpreted as reactive inflammation $(\mathrm{H} \& \mathrm{E}$, original magnification $\times 12.5$ and $\times 100$, respectively). (c) Immunohistochemical staining for cyclin D1 shows cyclin D1-positive cells in the infiltrates (immunoperoxidase cyclin D1, original magnification $\times 100$ ). Fluorescence in situ hybridization (FISH) analysis using a cyclin D1 gene break apart assay confirmed the presence of a break in the cyclin D1 locus, indicative for a t(11;14) (small insert in c). (d-h) Case 7: extranodal lymphoid infiltrates in the lung (d, e, H\&E, original magnification $\times 25$ and $\times 100$, respectively). (f) Immunohistochemical staining for cyclin D1 reveals scattered cyclin D1-positive cells in the infiltrates (immunoperoxidase cyclin D1, original magnification $\times 100$ ). (g) Proliferation is low (immunoperoxidase Ki67; original magnification $\times 100$ ). (h) Immunohistochemical staining for the transcription factor SOX11 shows nuclear positivity in the cyclin D1-positive cells (immunoperoxidase SOX11, original magnification $\times 100$ ).

Figures 2a-d). The fourth case was a 76-year-old male (case 8), who underwent hemicolectomy for colon cancer. In the appendix and the mesenterial lymph nodes, a dense infiltration of the mantle zones by cyclin D1-positive B cells was detected (Figures 2e-f). As the cyclin D1 + cells were not restricted to the inner mantle zone, this case was also classified as an early manifestation of mantle cell lymphoma with a mantle zone growth pattern rather than a mantle cell lymphoma 'in situ'. Eight months after the colectomy, the diagnosis of mantle cell lymphoma was established in a cervical lymph node. All four cases with early mantle cell lymphoma manifestations showed positive staining for SOX11. In total, 42 reactive lymph nodes of 13 patients were investigated in the group with subsequent mantle cell lymphoma diagnosis. However, in none of these cases the criteria for mantle cell lymphoma 'in situ' were fulfilled.

\section{FISH Analysis}

In four of six patients with preclinical extranodal manifestation of mantle cell lymphoma containing a sufficient number of aggregated cyclin D1-positive cells in the infiltrates, additionally performed FISH confirmed the presence of a break in the cyclin D1 gene locus, indicative for the chromosomal translocation $\mathrm{t}(11 ; 14)(\mathrm{q} 13 ; \mathrm{q} 32)$ (Figure 1c, insert).

\section{Clonality Analysis}

In four cases of preclinical mantle cell lymphoma manifestations (cases 1, 6, 7 and 9) with sufficient tissue left, a comparative clonality analysis with the manifest mantle cell lymphoma was performed. Two cases showed identical monoclonal peaks in the amplification of the CDR2 and CDR3 regions of the immunoglobulin heavy chain gene (Figure 3). In the remaining two cases, it was not possible to generate a clonal product from the microdissected preclinical mantle cell lymphoma infiltrates, probably due to the small numbers of cells detected in the immunohistochemical stainings for cyclin D1.

\section{Discussion}

Mantle cell lymphoma 'in situ' describes immunohistochemically detectable cyclin D1-expressing B cells in not expanded mantle zones of morphologically inconspicuous lymph nodes. ${ }^{7}$ In this study, we did not identify any case of mantle cell lymphoma 'in situ' in a series of 1292 unselected lymph nodes from patients without evidence of lymphoma, indicating a very low prevalence of this lesion in a population without history of lymphoma. This collective served as a surrogate for the prevalence in healthy individuals that cannot be screened.

The absence of mantle cell lymphoma 'in situ' in our series is in line with recent results in a small series of reactive lymph nodes, ${ }^{8}$ as well as the low prevalence of $\mathrm{t}(11 ; 14)$-positive $\mathrm{B}$ cells in the peripheral blood of a healthy population, which are detectable in $1-7 \%$ of mostly male adults. ${ }^{4}$ This prevalence is a magnitude lower than that of circulating $t(14 ; 18)$-positive cells, which were detected in 39 of 86 individuals (45\%) in the same analysis. Correspondingly, in a recent study of the same cohort analyzed in this study, we had 

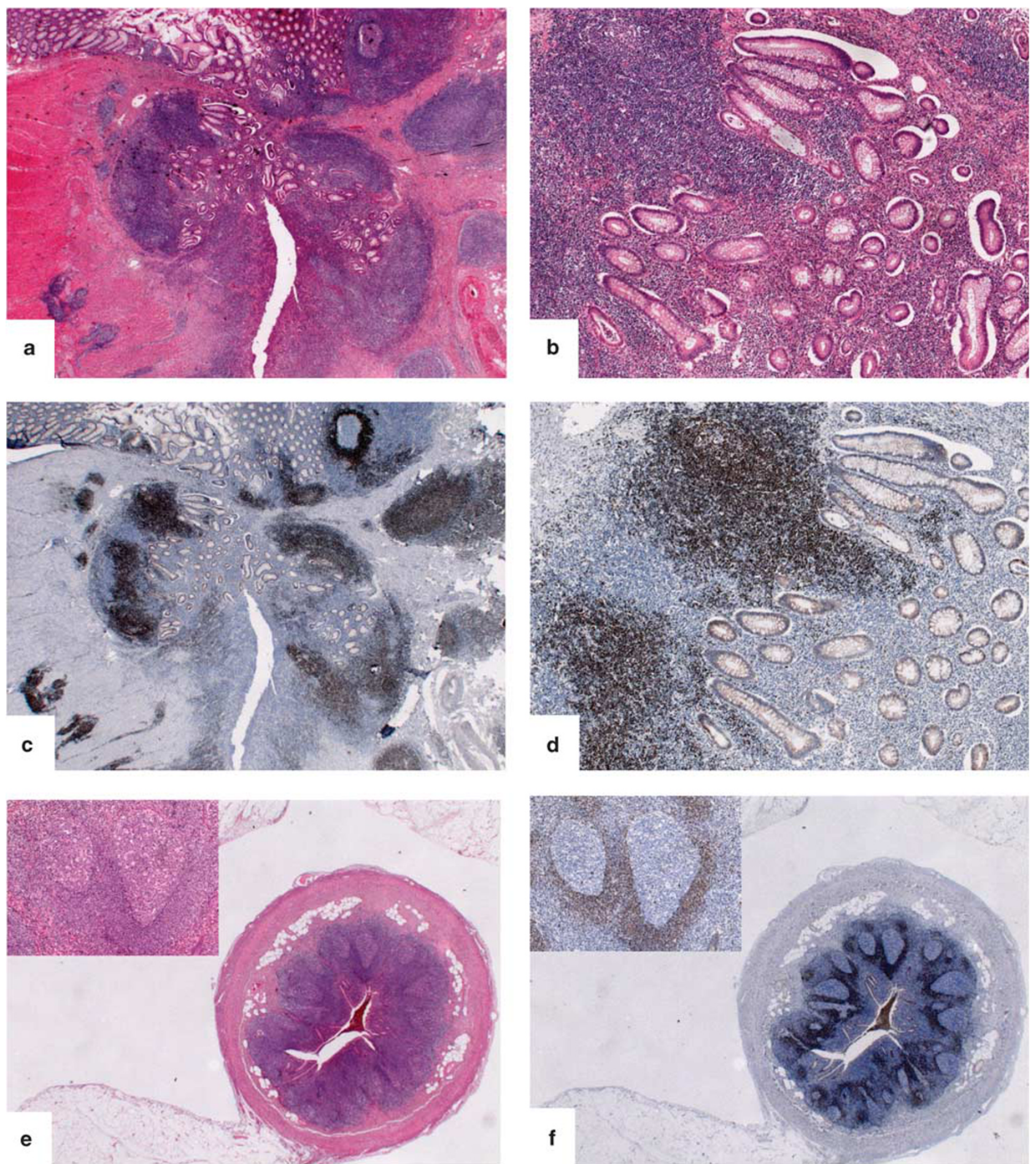

Figure 2 (a-d) Case 9: dense lymphocytic infiltrates surrounding a perforated colonic diverticulum are seen (a and b, H\&E, original magnification $\times 12.5$ and $\times 100$, respectively). (c, d) Staining for cyclin D1 detects strong cyclin D1 expression in the infiltrates, partly representing nodular infiltrates, partly showing a mantle zone pattern (immunoperoxidase cyclin D1, original magnification $\times 12.5$ and $\times 100$, respectively). (e, f) Case 8: (e) the appendix of an oncological hemicolectomy specimen showed a preserved architecture with reactive follicles in conventional morphology (H\&E, original magnification $\times 12.5$ and $\times 200$ insert). (f) Cyclin D1 staining reveals a dense infiltration of the complete mantle zones (Immunoperoxidase CyD1, original magnification $\times 12.5$ and $\times 200$ insert).

identified follicular lymphoma 'in situ' in 3 of the $132(2 \%)$ patients without history of lymphoma, indicating that the higher frequency of $\mathrm{t}(14 ; 18)$ positive circulating cells is paralleled by a higher incidence of follicular lymphoma 'in situ' compared with mantle cell lymphoma 'in situ'. ${ }^{10}$

In a second approach, we intended to detect the prevalence of mantle cell lymphoma 'in situ' in 

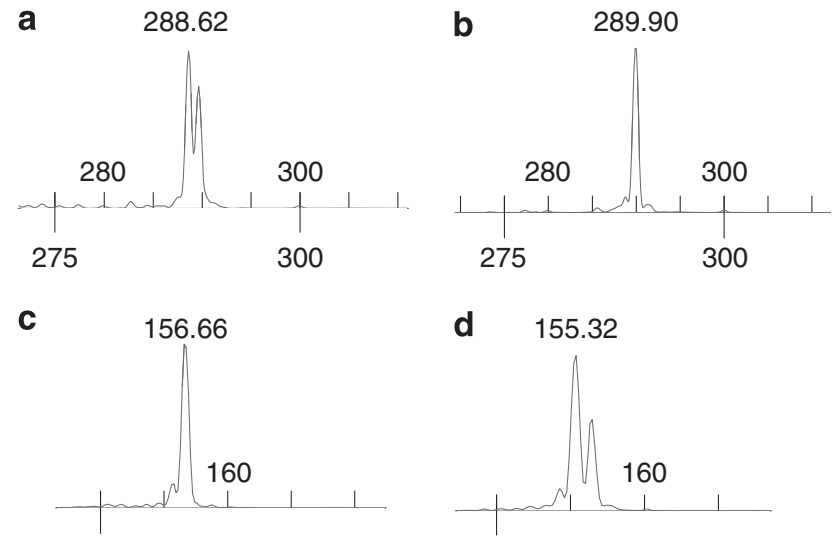

150

150

Figure 3 (a-d) Comparative clonality analysis of case 6. Amplification of the CDR2 region of the immunoglobulin heavy chain gene showed an identical monoclonal peak of 289 base pairs in the preclinical mantle cell lymphoma infiltrate (a) and the manifest mantle call lymphoma, diagnosed 3 months later (b). Amplification of the CDR3 region resulted in a monoclonal peak of 156 base pairs in the preclinical mantle cell lymphoma infiltrate (c) and of 155 base pairs the manifest mantle cell lymphoma (d).

reactive lymph nodes and other lymphatic tissue samples of patients with a subsequent diagnosis of overt mantle cell lymphoma, under the assumption that mantle cell lymphoma 'in situ' as putative precursor lesion might already be present before the appearance of clinical symptoms. Interestingly, in none of altogether 42 morphologically reactive lymph nodes available from 37 of 423 mantle cell lymphoma patients, a mantle cell lymphoma 'in situ' was detectable. This again is in contrast to our findings in follicular lymphoma, where we identified follicular lymphoma 'in situ' lesions in morphologically reactive lymphoid tissues in 9 of 55 follicular lymphoma patients (16\%) (Adam et al, unpublished data).

However, 10 of the 37 mantle cell lymphoma patients $(27 \%)$ with available non-neoplastic lymphoid tissues antedating the diagnosis of overt mantle cell lymphoma for $>2$ months had nodal or extranodal lymphoma manifestations. Four of these cases were classified as early mantle cell lymphoma with mantle zone growth pattern, because the infiltrates, although morphologically not obvious malignant lymphoma, already showed beginning distortion of the lymph node architecture or complete colonization of normal-sized follicle mantle zones. Of note, in one of the patients, the mantle cell lymphoma lesions were already present in several lymph nodes of a lung resection specimen $>7$ years before the diagnosis of overt mantle cell lymphoma. This highlights that some mantle cell lymphoma may show a very indolent course without requiring treatment.

The remaining six cases are of particular interest (see Table 1), because they represent a minimal, preclinical manifestation of mantle cell lymphoma, defined as cyclin D1-expressing B cells in morphologically reactive lymphoid infiltrates retrospectively detected in samples obtained $>2$ months before the diagnosis of overt mantle cell lymphoma. Comparative clonality analysis in two cases with sufficient tissue left showed an identical monoclonal peak in the preclinical infiltrates with the respective overt mantle cell lymphoma.

Although quantitatively comparable to mantle cell lymphoma 'in situ' lesions, these cases did not show the specific infiltration pattern to the inner mantle zone of reactive follicles as has been described for mantle cell lymphoma. ${ }^{8}$ In contrast to the wellknown predilection of mantle cell lymphoma for the gastrointestinal tract, the extranodal manifestations in our study included urinary bladder, prostate and stomach. ${ }^{12,13}$ Although this distribution pattern is certainly influenced by the availability of biopsy material from different sources, it indicates that mantle cell lymphoma cells disseminate throughout the organism already very early, during the preclinical stage of the disease. Of note, none of these patients did have a nodal manifestation of a mantle cell lymphoma 'in situ'. In line with these findings are recent reports on scattered cyclin D1-positive B cells in colonic and gastric mucosa biopsies identified retrospectively after the diagnosis of manifest mantle cell lymphoma. ${ }^{14,15}$ In the colon, these lesions were called mantle cell lymphoma 'in situ'. However, this observation might more precisely be termed a minimal, preclinical manifestation of mantle cell lymphoma, as the term in situ is meant to imply localization in the corresponding physiological compartment, the mantle zone of morphologically reactive $\mathrm{B}$-cell follicles.

Recently, nuclear expression of the transcription factor SOX11 has been identified as highly characteristic feature of mantle cell lymphoma, making this marker a useful additional diagnostic tool, particularly in cyclin D1-negative mantle cell lymphoma. ${ }^{16,17}$ Among non-Hodgkin lymphomas, only lymphoblastic lymphomas and Burkitt lymphomas can also express SOX $11 .{ }^{18}$ Of interest, in a recent report, lack of SOX11 has been identified by gene expression profiling in a subgroup of mantle cell lymphoma cases that showed indolent behaviour with long-term survival even without treatment, common leukemic presentation and splenomegaly, as well as a predominance of mutated immunoglobulin heavy chain genes and low levels of secondary genetic aberrations. ${ }^{19}$ In a recent report on 16 mantle cell lymphoma 'in situ', the authors found SOX11 expression in less than half of the cases and speculated that this might be an indicator of the commonly indolent, nonprogressive behaviour of these lesions. ${ }^{8}$ In contrast, all preclinical manifestations of mantle cell lymphoma with sufficient material detected in our study, irrespective of the subsequent time to manifest mantle cell lymphoma, as well as all cases of mantle cell lymphoma 'in situ' 
submitted to the Lymphoma Workshop of the XV Meeting of the European Association of Hematopathology and the Society of Hematopathology in Uppsala 2010 consistently expressed SOX11.20 Similarly, all four cases with early mantle cell lymphoma, including the case antedating the diagnosis of mantle cell lymphoma for 86 months, were SOX11-positive. We therefore believe that it is currently not warranted to use SOX11 staining as potential prognostic marker for early mantle cell lymphoma infiltrates in the diagnostic setting.

In summary, mantle cell lymphoma 'in situ' is a very rare lesion, both in the normal population and in reactive lymphoid tissues of patients with mantle cell lymphoma. However, early mantle cell lymphoma infiltrates or minimal accumulations of cyclin D1 + B cells can be observed commonly in tissues from mantle cell lymphoma patients, sometimes antedating lymphoma diagnosis for several years.

\section{Acknowledgements}

We thank Barbara Mankel, Annemarie Adam, Claudia Kloß and Robert Lambrecht for excellent technical assistance. This study was supported by the Karl-Thiemig-Stiftung, Germany (PA).

\section{Disclosure/conflict of interest}

The authors declare no conflict of interest.

\section{References}

1 Swerdlow SH, Campo E, Seto M, Müller-Hermelink HK. Mantle cell lymphoma. In: Swerdlow SH, Campo E, Harris NL, Jaffe ES, Pileri SA, Stein H, Thiele J, Vardiman JW (eds). World Health Organization Classification of Tumours of Haematopoietic and Lymphoid Tissues 4th edn, Vol., IARC Press: Lyon, 2008, pp 229-232.

2 Dolken G, Illerhaus G, Hirt C, Mertelsmann R. BCL-2/ $\mathrm{JH}$ rearrangements in circulating $B$ cells of healthy blood donors and patients with nonmalignant diseases. J Clin Oncol 1996;14:1333-1344.

3 Schuler F, Hirt C, Dolken G. Chromosomal translocation $\mathrm{t}(14 ; 18)$ in healthy individuals. Semin Cancer Biol 2003;13:203-209.

4 Hirt C, Schuler F, Dolken L, Schmidt CA, Dolken G. Low prevalence of circulating $\mathrm{t}(11 ; 14)(q 13 ; q 32)-p o s i-$ tive cells in the peripheral blood of healthy individuals as detected by real-time quantitative PCR. Blood 2004;104:904-905.

5 Marculescu R, Vanura K, Montpellier B, et al. Recombinase, chromosomal translocations and lymphoid neoplasia: targeting mistakes and repair failures. DNA Repair 2006;5:1246-1258.

6 Lecluse Y, Lebailly P, Roulland S, et al. t(11;14)positive clones can persist over a long period of time in the peripheral blood of healthy individuals. Leukemia 2009;23:1190-1193.

7 Aqel N, Barker F, Patel K, Naresh KN. In-situ mantle cell lymphoma-a report of two cases. Histopathology 2008;52:256-260.

8 Carvajal-Cuenca A, Sua LF, Silva NM, et al. In situ mantle cell lymphoma: clinical implications of an incidental finding with indolent clinical behavior. Haematologica 2011.

9 Richard P, Vassallo J, Valmary S, et al. 'In situ-like' mantle cell lymphoma: a report of two cases. J Clin Pathol 2006;59:995-996.

10 Henopp T, Quintanilla-Martinez L, Fend F, Adam P. Prevalence of follicular lymphoma in situ in consecutively analysed reactive lymph nodes. Histopathology 2011;59:139-142.

11 Trainor KJ, Brisco MJ, Wan JH, et al. Gene rearrangement in B- and T-lymphoproliferative disease detected by the polymerase chain reaction. Blood 1991;78: 192-196.

12 Geissmann F, Ruskone-Fourmestraux A, Hermine O, et al. Homing receptor alpha4beta7 integrin expression predicts digestive tract involvement in mantle cell lymphoma. Am J Pathol 1998;153:1701-1705.

13 Nakamura S, Matsumoto T, Takeshita $\mathrm{M}$, et al. A clinicopathologic study of primary small intestine lymphoma: prognostic significance of mucosa-associated lymphoid tissue-derived lymphoma. Cancer 2000;88:286-294.

14 Neto AG, Oroszi G, Protiva P, et al. Colonic in situ mantle cell lymphoma. Ann Diagn Pathol; advance online publication, 16 August 2011 (in press).

15 Dantoc MM, Eslick GD, Adams SS, Kalantar JS. Gastrointestinal mantle cell lymphoma-a tale of two endoscopies. J Gastrointest Cancer 2011.

16 Ek S, Dictor M, Jerkeman M, Jirstrom K, Borrebaeck CA. Nuclear expression of the non B-cell lineage Sox11 transcription factor identifies mantle cell lymphoma. Blood 2008;111:800-805.

17 Mozos A, Royo C, Hartmann E, et al. SOX11 expression is highly specific for mantle cell lymphoma and identifies the cyclin D1-negative subtype. Haematologica 2009;94:1555-1562.

18 Dictor M, Ek S, Sundberg M, et al. Strong lymphoid nuclear expression of SOX11 transcription factor defines lymphoblastic neoplasms, mantle cell lymphoma and Burkitt's lymphoma. Haematologica 2009;94: 1563-1568.

19 Fernandez V, Salamero O, Espinet B, et al. Genomic and gene expression profiling defines indolent forms of mantle cell lymphoma. Cancer Res 2010;70: 1408-1418.

20 Fend F, Cabecadas J, Gaulard P, et al. Early lesions in lymphoid neoplasia. J Hematopathol; advance online publication, 4 May 2012; doi:10.1007/s12308-0120148-6; e-pub ahead of print. 